BV acceptance of this article, the publishar or recipient acknowledges the U.S:AGavarnmęnt's right to CONF-83)2.57--1 retain a nonexclusive, royalty free license in and to any copyright

\title{
INFRARED MONITORING OF GYROTRON WINDOWS
}

H. Huey, N. Lopez, G. Hu, E. Cho1, \& L. Mundie, Consultant

COIfF $-831257--1$

Varian Associates, Inc.

Palo Alto, CA 94303

DES4 004442

\section{ABSTRACT}

A technique for monitoring the gyrotron output window surface temperature with an infrared camera while the gyrotron is in operation has been developed. The IR camera views the window through a perforated waveguide wall, and serves both as a guide for the safe operation at high average power of the tube, as well as an aid in the analysis of new window designs. Window temperatures were studied as a function of a number of parameters, including gun anode voltage, beam current, magnetic field, coolant flow, and load matching. The IR technique is applicable to many types of high average power microwave and millimeter wave tubes. Successful operation of the Varian $60 \mathrm{GHz}$ gyrotron to $214 \mathrm{~kW} \mathrm{CW}$ was guided by the infrared camera. Analyses on 28,56 and $60 \mathrm{GHz}$ Byrotrons have led to a number of design changes. A comparison with computer calculations is also presented.

\section{INTRODUCTION}

Windows for the transmission of high average power microwave and millimeter wave tubes such as the gyrotron are a key limitation in practical tube development. Thermal stresses can be calculated by computer modeling, but a number of conditions are often asssumed, such as the power density profile, the electromagnetic wave attenuation constant of the window material, the heat transfer coefficlent at the window and load matching. Uncertainties with overmoded waveguide, ghost modes, cooling fluid proflles, etc. reduce the accuracy of the calculations. To determine the actual window conditions, a technique for monitoring the temperature distribution over the window surface with an IR camera while the gyrotron is in operation has been developed. This technique is quite useful in analyzing window designs as well as gulding the tube to safe operating parameters. The ability to observe small hot spots due to tiny metallic specks on the window surface is also of great value in quality control and window failure
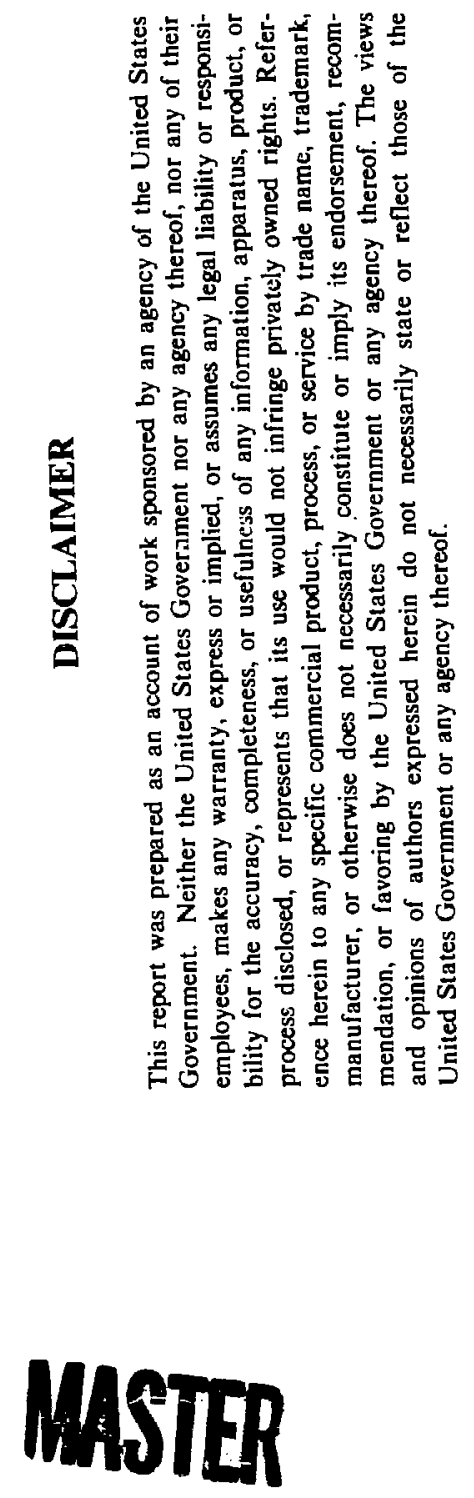

DISTRIBUTION OF THIS-BOCUMENT IS UHLIMITED 
prevention. The gyrotrons available for examination at Varian include $28 \mathrm{GHz}$ to $60 \mathrm{GHz}$ tubes at $200 \mathrm{~kW}$ pulsed and $\mathrm{CW}$. The output power of these tubes is in the TE 02 mode through a window in $2.5^{n}$ diameter wavegulde. 02

\section{SYSTEM DESIGN}

The technique uses an infrared camera (AGA-780) with on indium antimonide detector $(3-5 \mu \mathrm{m})$. The air side of the window is observed through a pattern (grid) of tiny holes (cutors for $180 \mathrm{GHz}$ ) in the output waveguide wall as 1llustrated in Figure 1. The thermal emissivity of the alumina window, which is a measure of the blackbody-like behavior at $3-5 \mu \mathrm{m}$, is $E_{w}=0.95$, so the IR measurement of the window is very much like a blackbody. This also implies that the measurement yields only the surface temperature of the window. A test to observe a $330^{\circ} \mathrm{C}$ object behind a sample window at room temperature confirmed the validity of the measurement. Reflections from the window are negligible due to the high emissivity. Reflections of the window from the internal waveguide walls occur at angles which appear external to the window edge, and thus can be neglected. To minimize the problem of external waveguide wall reflections, the outside waveguide wall is painted black. However, in order to reduce the thermal emission of the painted waveguide wall, a cool waveguide is required; room temperature is sufficient.

The system presently vieiss only about half of the window surface. Rotation of the camera about the waveguide axis pernits a view of the entire window.

The IR camera scans the window area and measures the photon flux. This flux, Ia, is a function of the window temperature at each point, the grid transmittance, $t_{g}$, and the grid reflection $r_{g}$, along the optical path. The operational equation is:

$$
I_{a}=I_{w} E_{w}+I_{g}\left(1-t_{B}-r_{g}\right)+I_{a m b} r_{g}
$$

Where $I_{w}, I_{g}$, $I_{a m b}$ are the blackbody equivalent intersities of the window, grid and ambient "background", respectively. A determination of the Brid transmission function is achieved by calibrating with a "blackbody" radiator of known 
temperature. Colibrating at two different temperatures helps to eliminate the reflection term in determining the transmission function.

The temperature resolution of the system depends on the rel-tive temperature difference between the waveguide and window as well as the grid transmission coefficient. For a waveguide at rocm temperature, the temperature resolution near the center of the window is about $1^{\circ} \mathrm{C}$ for a window temperature of $70^{\circ} \mathrm{C}$. It improves as the window temperature increases. Spatial resolution is better than $2 \mathrm{~mm}$ and hot spots $<1 \mathrm{~mm}$ are easily observed.

\section{RESULTS}

Measurements were first performed on 28 and 56 $\mathrm{GHz}$ CW Byrotrons. Temperature profiles show peaks near the window center (see Figure 2). Peak temperature as a funcision of output power is shown in Figure 3. A ilnear least squares $\mathrm{f} 1 \mathrm{t}$ appears to fit quite well. Similar results were cotained on other gyrotrons at different frequencies. A naive extrapolation of the peak window temperature at $200 \mathrm{~kW}$ output appears to be well below the boiling point of the Fr:-75 coolant ( $\sim 130^{\circ} \mathrm{C}$ at $\left.30 \mathrm{psi}\right)$. The variation of the peak window temperature for several operating parameters was checked. In particular, at $56 \mathrm{GHz}$, the FC-75 window coolant flow rate was found to be a crucia. parameter (but. not at $28 \mathrm{GHz}$ ). Figure 4 shows the variation of the peak window temperature as a function of the FC-75 flow rate for a number of output powers. The conservatively extrapolated curve at $130 \mathrm{~kW}$ shows that at 4 GPM, the temperature of the window can exceed the FC-75 boiling point. This was probably the cause of a previous window failure on the $X-5$ $60 \mathrm{GHz}$ gyrotron. Cooling the FC-75 was also found to reduce the peak window temperature. This would increase the safety margin at $200 \mathrm{~kW}$ operation for preventing boiling of the FC- 75 .

The $\mathrm{X}-660 \mathrm{GHz}$ gyrotron was safely guided to operation at $214 \mathrm{~kW} \mathrm{CW}$ by monitoring the window temperature with the IR system. Due to the wider dynamic range in the operational parameter space and higher operating temperatures on the $x 6$ than on previous Byrotrons, changes in the temperature prorile were easily discernable. Figure 5 illustrates the range of the peak window temperature (for constant output power) as a function of the magnetic field. This suggests mode conversion is occurring. The window temperature variation 
appears to be due to a change in the phase of the modes at the window anj not due to a change in mode content. Ghost modes in the window might also cause this phenomenon. The concurrent use of mode samp?es will provide additional information on this.

\section{CONCLUSION}

The IR monitoring method described above has proved to be invaluable to the development of the $60 \mathrm{GHz}, 200 \mathrm{~kW} \mathrm{CW}$ gyrotron. It is particularly useful in evaluating windor designs and revealing tiny metallic specks that may have fallen onto the window surface. The technique is presently being simplified for use with both development and production testing. Integration into a tesc set is planned for further gyrotron development work.

(1)

The $60 \mathrm{GHz}$ gyrotron oscillator is being developed under contract with Oak Ridge National Laboratory, operated by Union Carbide Corporation for the U.S. Department of Energy under prime contract

W-7405-eng-26. 
FIGURE 1. GRID DESIGN

FIGURE 2. RADIAL TEMPERATURE PROFILE

FIGURE 3. TEMPERATURE US OUTPUTPOWER

FIGURE 4. TEMPERATURE US FC-75 FLOW

FIGURE 5. PEAK WINDOW TEMPERATURE US MAIN MAGNET 1 CURRENT 


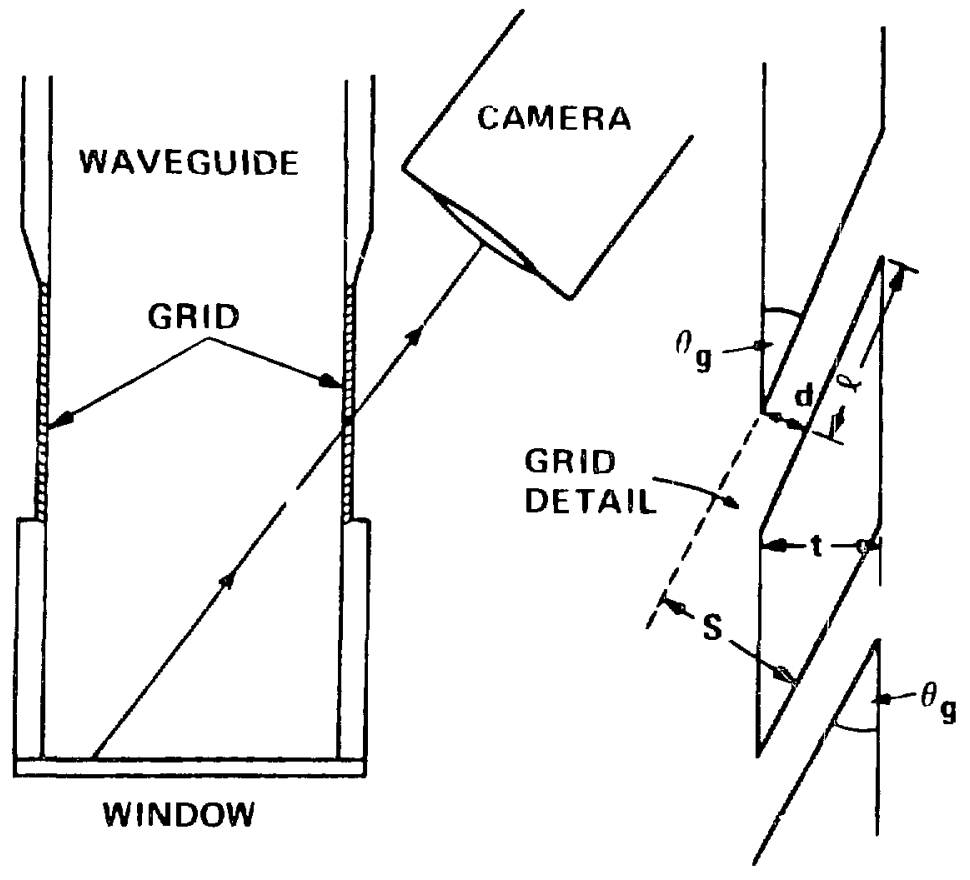

Figme' 


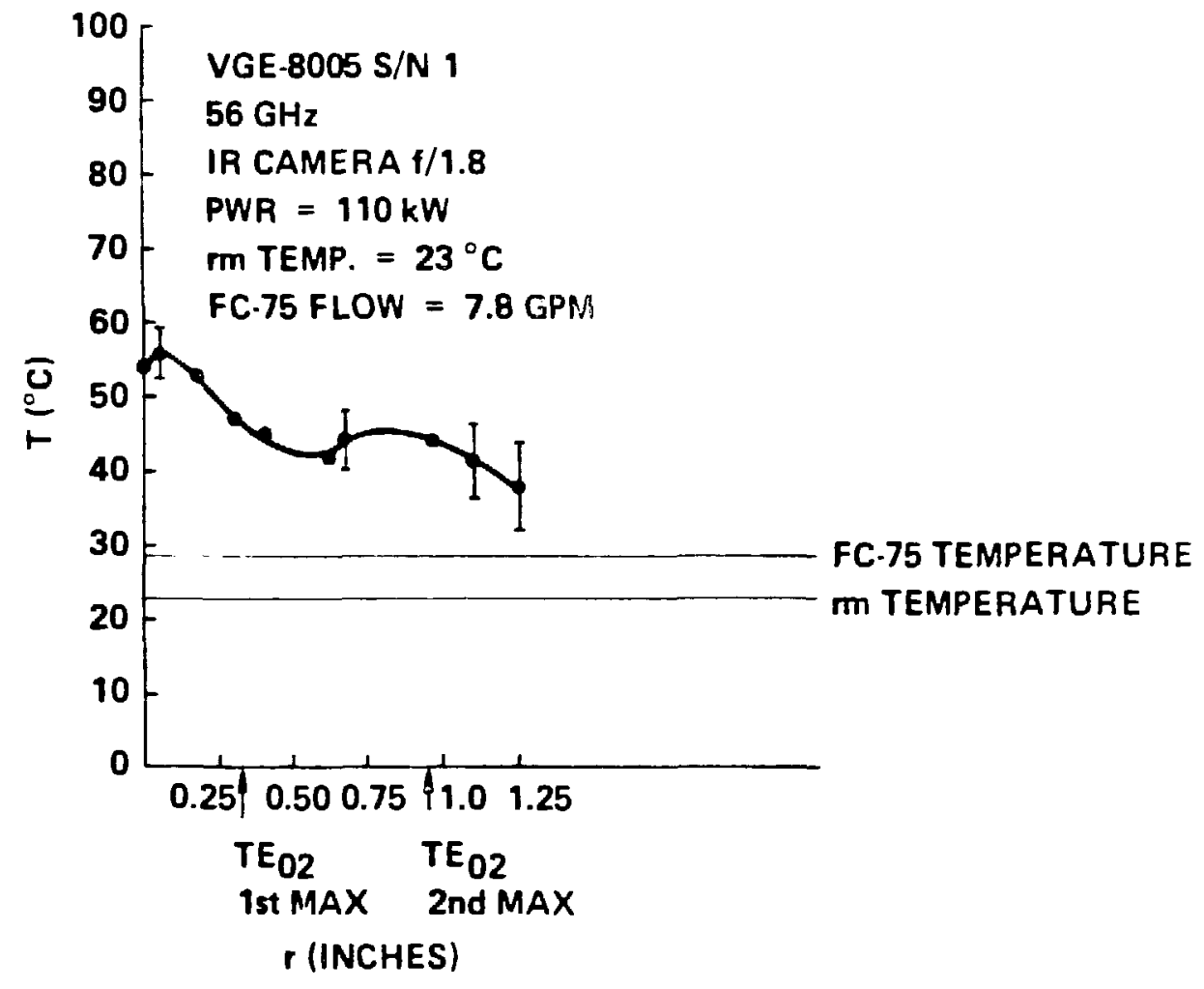




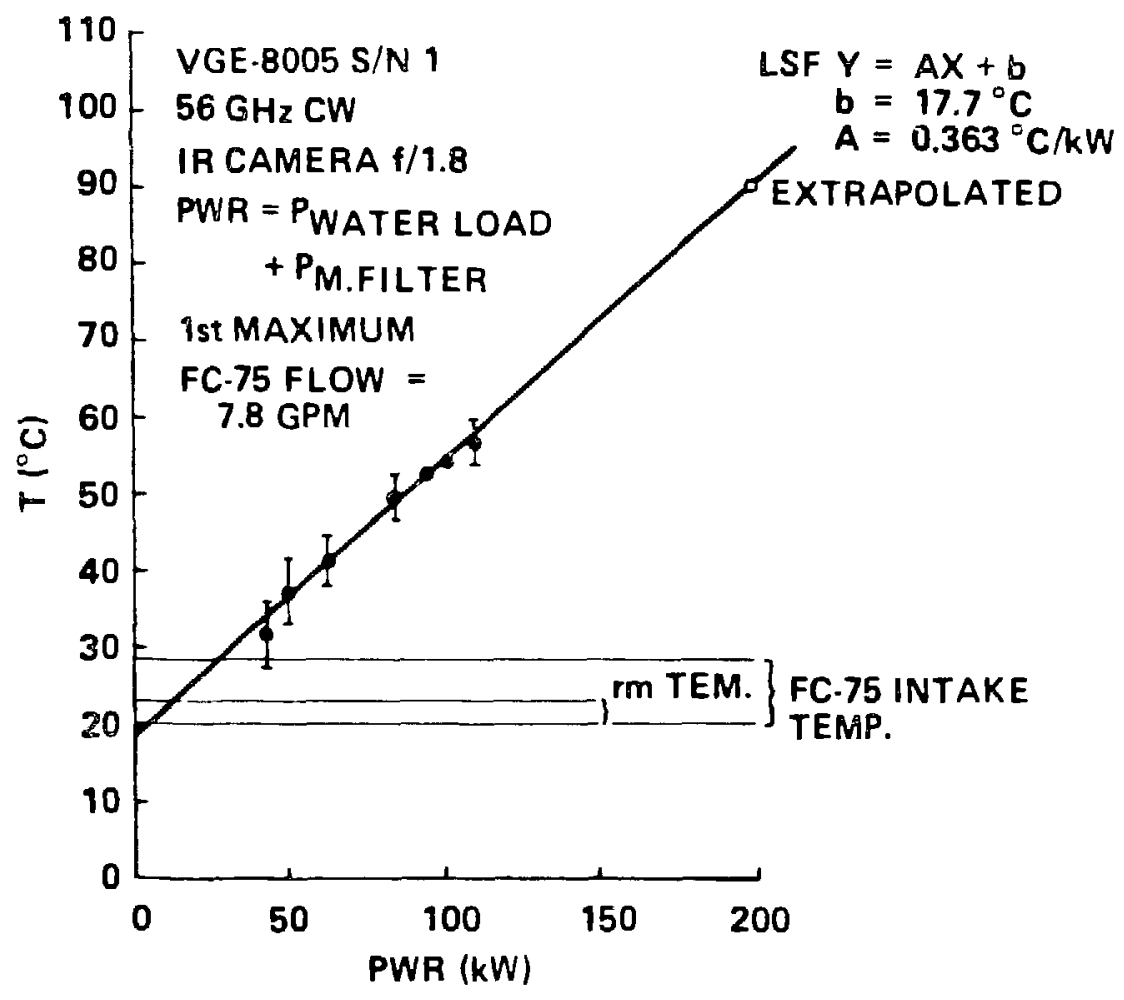

$=$ agine 3 


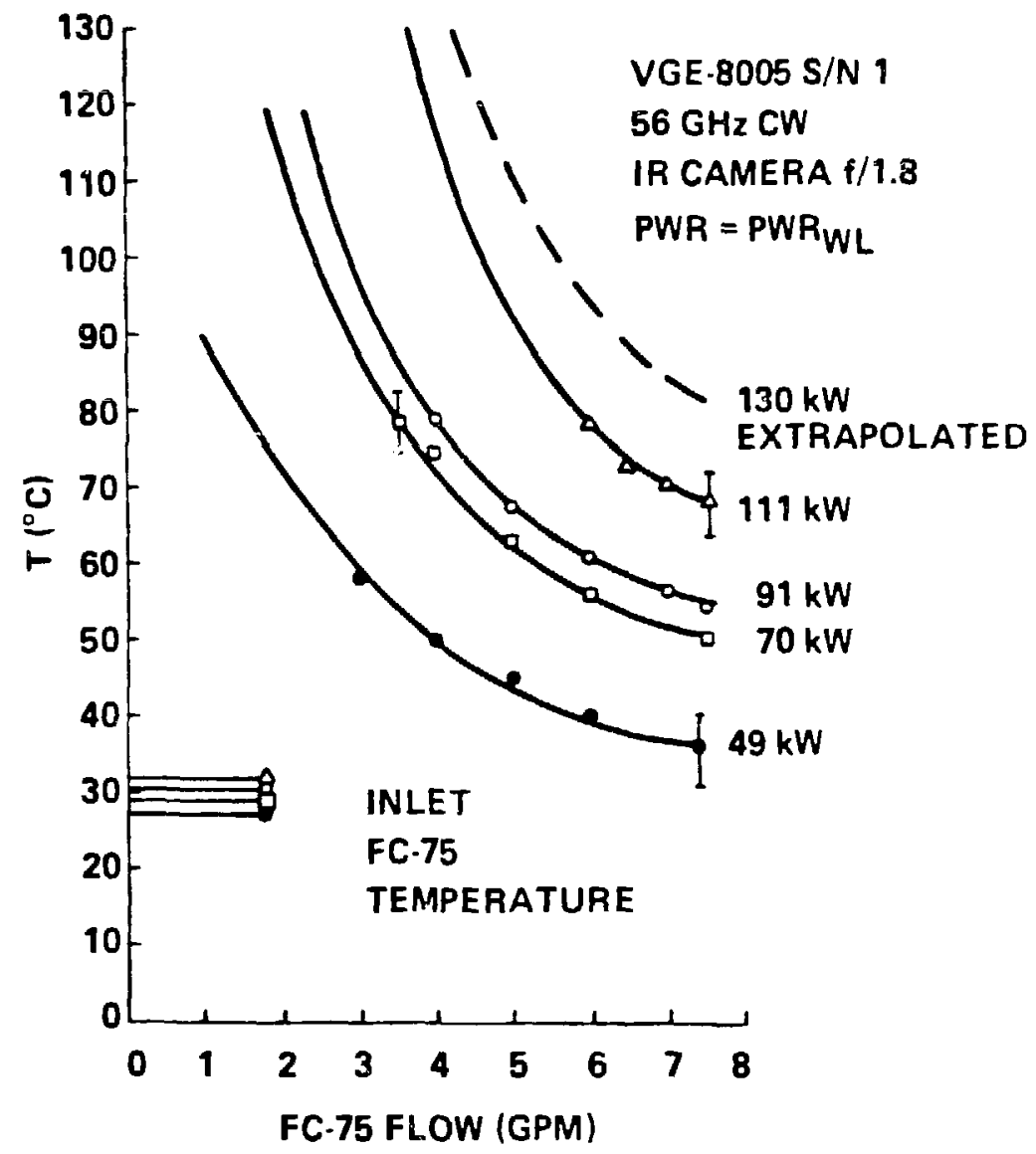

Itiginet 4 


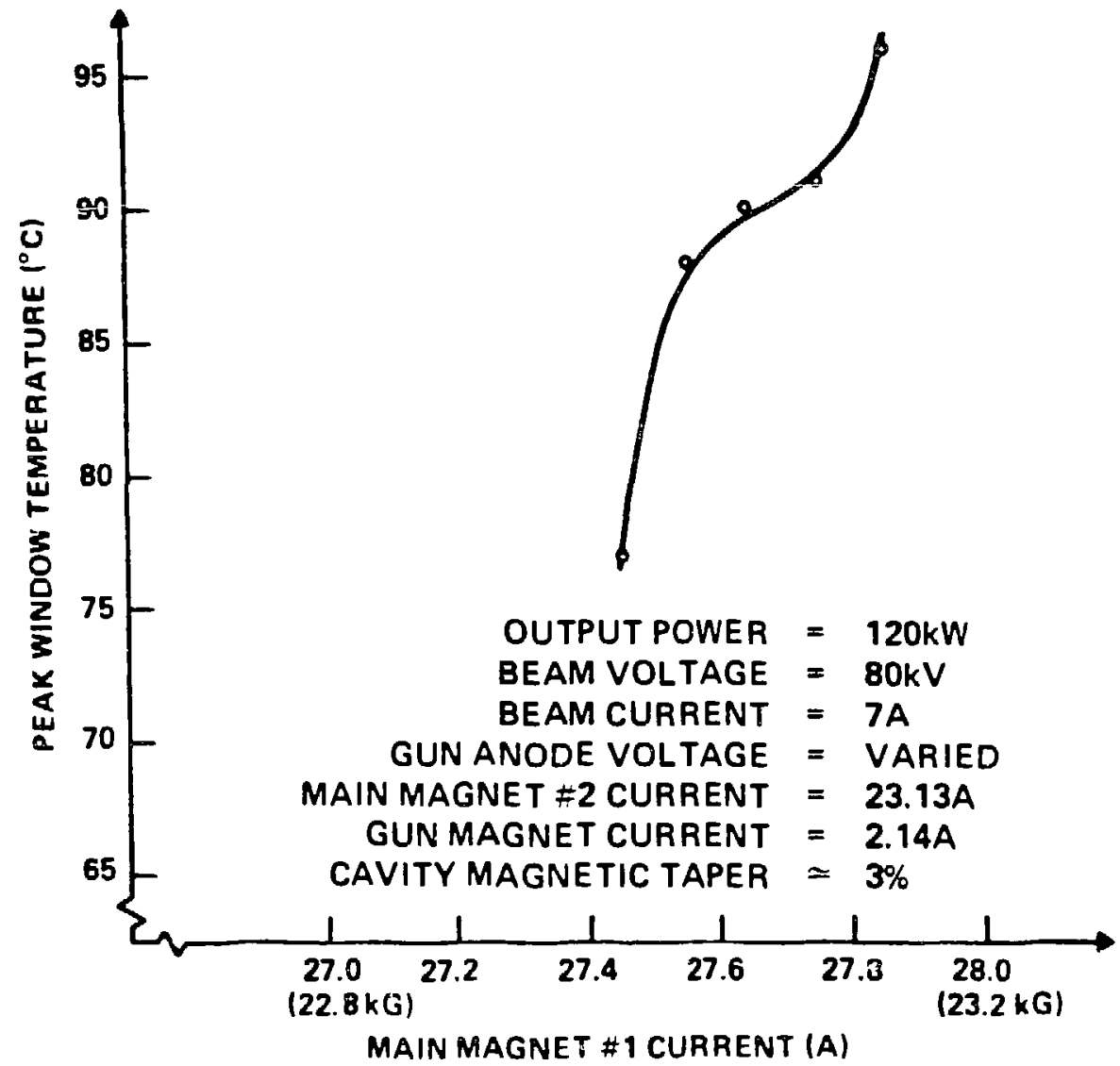

7 zinse 5 